\title{
Randomized trial of polychromatic blue-enriched light for circadian phase shifting, melatonin suppression, and alerting responses.
}

\author{
J. P. Hanifin \\ Thomas Jefferson University \\ S. W. Lockley \\ Brigham and Women's Hospital, Harvard Medical School \\ K. Cecil \\ Thomas Jefferson University \\ K. West

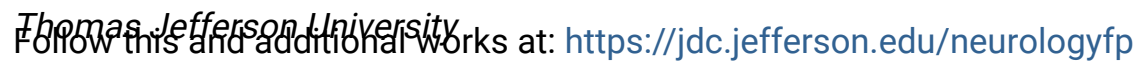 \\ 中abatonatke Neurology Commons \\ Theras is feferso Uwiversitw access to this document benefits you
}

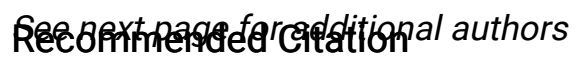

Hanifin, J. P.; Lockley, S. W.; Cecil, K.; West, K.; Jablonski, M.; Warfield, B.; James, M.; Ayers, M.; Byrne, B.; Gerner, E.; Pineda, C.; Rollag, M.; and Brainard, G. C., "Randomized trial of polychromatic blue-enriched light for circadian phase shifting, melatonin suppression, and alerting responses." (2019). Department of Neurology Faculty Papers. Paper 181.

https://jdc.jefferson.edu/neurologyfp/181

This Article is brought to you for free and open access by the Jefferson Digital Commons. The Jefferson Digital Commons is a service of Thomas Jefferson University's Center for Teaching and Learning (CTL). The Commons is a showcase for Jefferson books and journals, peer-reviewed scholarly publications, unique historical collections from the University archives, and teaching tools. The Jefferson Digital Commons allows researchers and interested readers anywhere in the world to learn about and keep up to date with Jefferson scholarship. This article has been accepted for inclusion in Department of Neurology Faculty Papers by an authorized administrator of the Jefferson Digital Commons. For more information, please contact: JeffersonDigitalCommons@jefferson.edu. 


\section{Authors}

J. P. Hanifin, S. W. Lockley, K. Cecil, K. West, M. Jablonski, B. Warfield, M. James, M. Ayers, B. Byrne, E. Gerner, C. Pineda, M. Rollag, and G. C. Brainard 


\title{
Randomized Trial of Polychromatic Blue-Enriched Light for Circadian Phase Shifting, Melatonin Suppression, and Alerting Responses
}

\author{
J. P. Hanifin ${ }^{a^{*}}$, S. W. Lockley ${ }^{b}$, K. Cecil ${ }^{a}$, K. West ${ }^{a}$, M. Jablonski ${ }^{a}$, B. Warfield ${ }^{a}$, M.

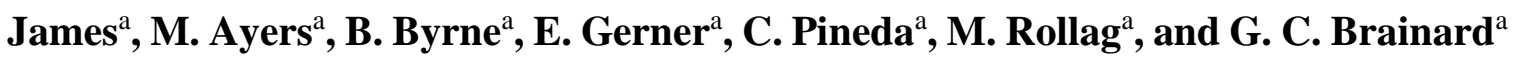

${ }^{a}$ Department of Neurology, Thomas Jefferson University, Philadelphia, PA 19107

${ }^{b}$ Division of Sleep and Circadian Disorders, Departments of Medicine and Neurology, Brigham and Women's Hospital, Boston, MA 02115; Division of Sleep Medicine, Harvard Medical School, Boston, MA 02115.

*Corresponding author at: Department of Neurology, Thomas Jefferson University, 1025

Walnut Street, Suite 507, Philadelphia, PA 19107 
Wavelength comparisons have indicated that circadian phase-shifting and enhancement of subjective and EEG-correlates of alertness have a higher sensitivity to short wavelength visible light. The aim of the current study was to test whether polychromatic light enriched in the blue portion of the spectrum $(17000 \mathrm{~K})$ has increased efficacy for melatonin suppression, circadian phase-shifting, and alertness as compared to an equal photon density exposure to a standard white polychromatic light $(4000 \mathrm{~K})$. Twenty healthy participants were studied in a time-free environment for 7 days. The protocol included two baseline days followed by a 26 -h constant routine (CR1) to assess initial circadian phase. Following CR1, participants were exposed to a full-field fluorescent light $\left(1 \times 10^{14}\right.$ photons $/ \mathrm{cm}^{2} / \mathrm{s}$, $4000 \mathrm{~K}$ or $17000 \mathrm{~K}, \mathrm{n}=10 /$ condition) for $6.5 \mathrm{~h}$ during the biological night. Following an 8 $\mathrm{h}$ recovery sleep, a second 30-h CR was performed. Melatonin suppression was assessed from the difference during the light exposure and the corresponding clock time $24 \mathrm{~h}$ earlier during CR1. Phase-shifts were calculated from the clock time difference in dim light melatonin onset time (DLMO) between CR1 and CR2. Blue-enriched light caused significantly greater suppression of melatonin than standard light ((mean \pm SD) $70.9 \pm 19.6 \%$ and $42.8 \pm 29.1 \%$, respectively, $\mathrm{p}<0.05$ ). There was no significant difference in the magnitude of phase delay shifts. Blue-enriched light significantly improved subjective alertness $(\mathrm{p}<0.05)$ but no differences were found for objective alertness. These data contribute to the optimization of the short wavelength-enriched spectra and intensities needed for circadian, neuroendocrine and neurobehavioral regulation.

\section{Keywords}

Light response 
Circadian rhythm
Alertness
Melatonin

\section{Introduction}

The human circadian pacemaker is exquisitely responsive to ocular light exposure [1]. Photic information is transduced by the retinohypothalamic tract to the suprachiasmatic nucleus $(\mathrm{SCN})$ and then to the pineal gland via a multisynaptic pathway [2]. The SCNpineal, but not the retinae-SCN pathways need to be intact for the secretion of melatonin, even in the absence of light $[3,4]$. By way of this neuroanatomy, cycles of light and dark which are detected through the eyes entrain SCN neural activity which, in turn, entrains the rhythmic synthesis of multiple physiological, endocrinological, metabolic and behavioral systems including melatonin secretion from the pineal gland [5].

In virtually all species including humans, high levels of melatonin are secreted during the night and low levels are secreted during the day [6]. Ocular light exposure affects melatonin secretion in two major ways -light exposure during the biological night causes the acute suppression of melatonin [7] and light exposure throughout the 24-hour day shifts its rhythm according to a Phase Response Curve [8]. The strong circadian control of melatonin and its sensitivity to light timing mean that melatonin is often used as a marker of the circadian clock [9].

Light is detected primarily by a specialized subset of intrinsically photosensitive retinal ganglion cells (ipRGCs) $[10,11,12,13]$. These non-rod, non-cone photoreceptors express 
the photopigment melanopsin which has a short wavelength peak sensitivity around 480 $\mathrm{nm}[14,15]$.

Using this defined spectral sensitivity of the melanopsin photopigment in ipRGCs, multiple studies have examined the spectral sensitivity of melatonin suppression, circadian phase shifting, and the acute effects of alertness using narrowband (15 $\mathrm{nm}$ or greater halfpeak bandwidth) or monochromatic (less than $15 \mathrm{~nm}$ halfpeak bandwidth) light sources. Monochromatic blue light has been shown to cause greater circadian phase shifting and acute alerting responses over monochromatic green light $[16,17,18,19,20]$.

Studies have also documented short-wavelength sensitivity for neuroendocrine effects using broad spectrum polychromatic blue-enriched light evoking stronger melatonin suppression than those with relatively less short-wavelength light [21,22]. In both of these studies, equal photopic lux bright light exposures of either 1,000 lux [22] or 2,500 lux [21] at high CCT (6480-6500K) caused greater increases in melatonin suppression and increases core body temperature than low CCT (3000-3150 K) broad spectrum polychromatic light. Sato and colleagues reported that a 2 hour light exposure in the early morning caused significant acceleration in the rise of core body temperature and fall of salivary melatonin secretion from the blue-enriched, high CCT condition [21]. Evening light exposures of 5 hours were employed by Morita and Tokura causing significant suppression of the nocturnal rise urinary melatonin and the fall of core body temperature in the high CCT group [22]. These carefully done initial studies, however, were limited in that they examined only the acute neuroendocrine effects of relatively intense polychromatic light sources. We built on these results to examine both acute and circadian neuroendocrine 
responses as well as neurobehavioral differences using a standard light source at more common lower room illuminances

In addition to highly controlled laboratory studies, several real-world applications in schools and offices using both static and dynamic lighting manipulations involving blueenriched light have demonstrated increased subjective measures of alertness and affect as well as improvements in standard tests of cognitive processing speed, concentration and reading ability in blue-enriched lighting conditions[23,24,25,26,27]. For example, office installation of the fluorescent lamps used in this study on two floors with participants being exposed in a counter-balanced order resulted in statistically significant improvements in self-reported measures of alertness, mood, performance, evening fatigue, irritability, concentration and eye discomfort during the month of $17000 \mathrm{~K}$ exposure as compared to $4000 \mathrm{~K}$ [23]. Mott et al. (2012) studied third grade students (age 7-8 years) under the Normal (500 lux, 3500K) versus Focus (1000 lux, 6500K) light conditions and found that the higher CCT lighting was reported to improve oral reading fluency when assessed over a full calendar year [25].

Recently, we conducted a within-subjects study that established full-range fluenceresponse curves to three types of fluorescent lamps that differed in their relative emission of light in the short wavelength end of the visible spectrum between 400 and $500 \mathrm{~nm}$ demonstrating that increasing corneal irradiances of light evoked progressively increasing suppression of nocturnal melatonin. Comparison of these fluence-response curves supports the hypothesis that polychromatic fluorescent light is more potent for melatonin regulation when enriched in the short wavelength spectrum [28]. Building on these data, we tested the hypothesis that blue-enriched polychromatic fluorescent light (17000 K) can be more 
effective than standard white fluorescent light (4000 K) light for eliciting melatonin suppression, enhancement of neurobehavioral function and phase shifting in healthy human participants. This carefully controlled comparison of a high color temperature polychromatic light source was performed under commonly occurring room illuminances while balancing for photon density.

\section{Materials and Methods}

\subsection{Participants}

A total of 11 males and 9 females (mean age \pm SD of $22.1 \pm 1.8$ years, range -19 to 26 years) were studied in the Light Research Laboratory of Thomas Jefferson University between July 2007 and August 2008. The study was approved by the Institutional Review Board of Thomas Jefferson University and all participants gave written informed consent prior to entering the protocol. All participants underwent psychological, toxicological, physical, and ophthalmological exams including color vision testing. For at least 10 days prior to entry into the seven-day protocol participants maintained a self-selected 8-hour sleep/wake schedule with calls to a time- and date-stamped voicemail at bedtime and wake. Participants also wore an actigraph (BASIC Motionlogger, Ambulatory Monitoring, Inc., Ardsley, NY) to verify bed and wake times during this time. The exclusion criteria included no use of recreational, over-the-counter, or prescription medications inclusive of caffeine and alcohol in the 10 days prior to admission. Toxicological screening for drugs of abuse, caffeine and alcohol as well as pregnancy testing, basic metabolic panel, thyroid function, and a complete blood count was conducted during screening and on the day of entry in the facility. Both groups were gender balanced (5M, 5F in $17000 \mathrm{~K}$ group and 4M, $6 \mathrm{~F}$ in $4000 \mathrm{~K}$ group) and the testing of two sleep parameters from actigraphy revealed no 
differences (Total Sleep Time and Awakenings) from actigraphy revealed no differences $(\mathrm{p}=0.23$ and $\mathrm{p}=0.70$, respectively).

\subsection{Protocol design}

Figure 1 provides a diagrammatic representation of the 7-day inpatient protocol. This protocol was adapted from the 9-day protocol used at the Brigham and Women's Hospital [16]. Participants lived in a time-free environment (no windows, timepieces, TV, or internet access with continual supervision by trained staff) and remained in their assigned room for the duration of the study. During the constant-routine, participants remained awake in dim light ( $<5$ lux $)$ in a semi recumbent position while under direct supervision with isocaloric meals (basal energy expenditure x 1.3) being served every two hours.

\subsection{Study lighting conditions}

Ambient light in the facility was produced by ceiling-mounted standard cool-white (4100 K CCT) $40 \mathrm{~W}$ fluorescent lamps (F40T12/841ALTO, Philips Lighting, B.V., Eindhoven, Netherlands) placed above matte white acrylic 0.080-inch diffuser panels and controlled by a full range dimming system (Model \#HLT-2000/3 Dimmer Module with HILUME Electronic dimming ballast OPSCU Series, DP-1 dimmer panel, VA-3-4A Control Panel, Lutron Corp., Coopersburg, PA). The light intensities in the study rooms were $<80$ lux maximal (at a height of $122 \mathrm{~cm}$ in the vertical plane) on study day 1 and during the first eight hours of study day 2. For the rest of the waking hours of the study, participants were kept in constant dim light with illuminances $<5$ lux in the vertical plane. Eight-hour sleep opportunities scheduled at the average of the 10 days prior to admission occurred in 
complete darkness. Daily illuminance/irradiance measures were taken using an IL1400BL radiometer/photometer (International Light Technologies, Inc., Peabody, MA). This meter had either a model SEL033/Y/W detector or to provide photopic illuminance response or SEL033/F/W to provide flat irradiance response and each was annually given a full scanned calibration. All calibrations were traceable to the U.S. National Institute of Standards and Technology.

Experimental polychromatic light exposures occurred on the night of study day 4 when participants underwent a 6.5-hour light exposure (LE) that began 9.25 hours before their habitual wake time. Light exposure was timed to correspond to approximately $6.75 \mathrm{~h}$ before core body temperature minimum, a phase where previous studies produced phase delays [16,19]. The 4' x 4' light exposure system held both sets of $54 \mathrm{~W}$ fluorescent lamps in each. A diffuser cover on the front of the panel allowed for a uniform field of light exposure for the subject. The panel was attached to an analog dimmer switch to adjust intensity. The lamps, as well as the lighting panel unit, were constructed and donated by Philips Lighting, B.V. (Eindhoven, Netherlands). An additional neutral density filter panel (0.3 ND 50\% transmission) that covered the entire light panel surface was used to further adjust the intensity of $17000 \mathrm{~K}$ light source (Rosco Laboratories, Stamford, CT). Experimental illuminance/irradiance measures were taken using the IL-1400BL radiometer/photometer previously described which was held in place by a clear, plastic holder attached in an ophthalmologic head holder $30 \mathrm{~cm}$ from the panel at approximate eye level of the participants. Figure 2 shows the spectral power distributions emitted by the $4000 \mathrm{~K}$ and $17000 \mathrm{~K}$ experimental lamps. 
Participants were randomly assigned on the day of entry to experimental polychromatic light from a $4000 \mathrm{~K}$ or a $17000 \mathrm{~K}$ fluorescent lamp ( $\mathrm{N}=10$ per condition). The target intensity of the $17000 \mathrm{~K}$ lamp was chosen from fluence-response curves for short-duration (90-minute) melatonin suppression testing [28]. The $\mathrm{ED}_{90}$, or $90 \%$ of the saturating dose of light for melatonin suppression for the $17000 \mathrm{~K}$ lamp, was chosen for this study. This resulted in an equal photon density of $1 \times 10^{14}$ photons $/ \mathrm{cm}^{2} / \mathrm{s}$ for both exposure conditions. The equivalent irradiance/illuminance of light for the $4000 \mathrm{~K}$ and $17000 \mathrm{~K}$ lamps were $40.7 \mu \mathrm{W} / \mathrm{cm}^{2}$ (134.3 lux) and $50.0 \mu \mathrm{W} / \mathrm{cm}^{2}$ (128.9 lux), respectively. The average irradiances $( \pm$ SEM) measured every 30 minutes over the 6.5 h exposure were $40.86 \pm 0.12$ $\mu \mathrm{W} / \mathrm{cm}^{2}$ for the $4000 \mathrm{~K}$ exposure and $49.99 \pm 0.07 \mu \mathrm{W} / \mathrm{cm}^{2}$ for the $17000 \mathrm{~K}$ exposure. For 140 minutes prior to and for the full duration of the light exposure participants remained seated. Participants wore blindfolds for approximately 30 minutes prior to light exposure while lights stabilized and intensities were verified. Participants were seated $30 \mathrm{~cm}$ in front of the light panel with their chin placed in an ophthalmologic head holder and monitored continuously. Participants were asked to maintain a fixed gaze toward the panel for 90 minutes before resting their head and neck out of the headholder for 10 minutes while remaining seated. This sequence was repeated throughout the entire $6.5 \mathrm{~h}$ exposure.

\subsection{Sleepiness and performance assessments}

During every hour of wakefulness, participants completed the Karolinska Sleepiness Scale (KSS) [29], and visual and auditory psychomotor vigilance tasks (PVTs) [30,31] using a personal digital assistant (PDA) (Tungsten E2, Palm, Inc, Sunnyvale, CA). This modified visual PVT lasted for five minutes, at the end of which the mean reaction time 
for that trial was displayed for the subject. PDA light measures taken at 12 inches from the eye were 1.2 lux and at 24 inches were 0.6 lux, The main measures for each trial for each subject were mean reaction time in milliseconds and number of lapses greater than 500 milliseconds (i.e. number of times the subject took 500 milliseconds or longer to react to the target appearing) $[30,32,33]$. The auditory PVT was completed on a PVT-192 by Ambulatory Monitoring, Inc. (Ardsley, NY). The auditory PVT trial was 10 minutes in length. The main measures for each trial for each subject were mean reaction time in milliseconds and number of lapses greater than 400 milliseconds [31].

\subsection{Sample collection}

Blood samples $(3 \mathrm{ml})$ were collected through an indwelling intravenous catheter located in a forearm vein into $3 \mathrm{ml}$ polystyrene tubes which contained $5.4 \mathrm{mg}$ of $\mathrm{K} 2$ ethylenediaminetetraacetic acid (EDTA) (BD Diagnostics, Franklin Lakes, NJ). Plasma was separated by refrigerated centrifugation, aliquoted into cryogenic vials and stored at $20^{\circ} \mathrm{C}$. Plasma melatonin samples were collected every 60 minutes during constant-routine periods on Days $3 / 5$ and every 20 minutes during light exposure. Plasma melatonin concentrations were assayed by radioimmunoassay using antiserum described by Rollag and Niswender [34].

Saliva samples ( $2 \mathrm{ml})$ were collected with the "Salivette" sampling device (Sarstedt, Inc., Hayward, CA). Specimens were centrifuged and aliquoted into cryogenic vials for storage at $-20^{\circ} \mathrm{C}$ until assay. Salivary melatonin samples were collected every 60 minutes during constant-routine periods on Days 3/5 and during light exposure. Salivary melatonin 
concentrations were assayed by radioimmunoassay [35]. Salivary analyses were used as a backup measure when plasma samples were missed due to IV line failure.

\subsection{Melatonin assays}

The inter-assay coefficient of variation from the 15 plasma assays run for this experiment using the assay from Rollag and Niswender [34] was 17.0\%. Coefficient of variation calculated from a control sample of $100 \mathrm{pg} / \mathrm{ml}$ assayed had $12.3 \%$ for intra-assay coefficient of variation. The minimum detection limit of this assay is $0.5-2.0 \mathrm{pg} / \mathrm{ml}$ melatonin. The inter-assay coefficient of variation from the 7 salivary assays run for this experiment using the assay from Vaughan [35] was between 8-12\%. Coefficient of variation calculated from control samples of 1.83 and $18.99 \mathrm{pg} / \mathrm{ml}$ assayed had $2.7 \%$ and $6.9 \%$ intra-assay coefficient of variation respectively. The minimum detection limit of the salivary assay is $0.5-2.0 \mathrm{pg} / \mathrm{ml}$ melatonin.

\subsection{Statistics}

Melatonin suppression (mean $\pm \mathrm{SD}$ ) was calculated from the difference in area under the curve (AUC) between melatonin profiles during light exposure and the corresponding clock times during the previous melatonin cycle on CR1 [16]. Unpaired, two tailed t-tests were used to compare differences in melatonin suppression by exposure to $17000 \mathrm{~K}$ lamps compared to $4000 \mathrm{~K}$ lamps.

$\mathrm{DLMO}_{25}$ was calculated for each subject defined from $25 \%$ of the fitted three-harmonic peak-to-trough amplitude of the melatonin rhythm during the first constant routine. The magnitude of phase-shift was determined from differences in clock time between $\mathrm{DLMO}_{25}$ 
during the first constant routine (CR1) as compared to the second constant routine (CR2) [16]. Unpaired, two tailed t-tests were used to compare differences in phase by exposure to $17000 \mathrm{~K}$ lamps compared to $4000 \mathrm{~K}$ lamps.

The data from the visual PVT and the auditory PVT-192 devices were analyzed using mixed ANOVA analysis comparing light sources and time was completed using SAS 9.0 (SAS, Cary, NC).

To determine sample size a priori, data from a previous study of the phase shifting effects of $460 \mathrm{~nm}$ and $555 \mathrm{~nm}$ monochromatic light were used to perform a power analysis [16]. Using these data, a 1-h phase shifting difference was assumed, with a standard deviation of $0.62 \mathrm{~h}, \alpha$ value of 0.05 , and $\beta$ value of 0.9 . With these assumptions, 10 participants per group were calculated to be needed to detect the $1 \mathrm{~h}$ phase difference [36].

\subsection{Results}

\subsection{Melatonin suppression}

As shown in Figure 3, all participants exposed to blue-enriched $(17000 \mathrm{~K})$ polychromatic fluorescent light had at least $29 \%$ melatonin suppression over the entire $6.5 \mathrm{~h}$ light exposure (range 29-91\%). Suppression was more variable among participants exposed to the standard $(4000 \mathrm{~K})$ polychromatic fluorescent light at the same photon density (range 0$82 \%$ ), including 2 individuals with virtually no melatonin suppression. On average, exposure to $6.5 \mathrm{~h}$ of $17000 \mathrm{~K}$ light caused a significantly greater suppression of melatonin (mean \pm SD, $70.9 \pm 19.6 \% ; n=10)$ compared with $4000 \mathrm{~K}$ light $(42.8 \pm 29.1 \% ; n=10)$ $(p<0.05)$. The time course of the melatonin suppression response also differed between the groups. In the $17000 \mathrm{~K}$ condition, the light suppressed melatonin for the entire exposure duration and did not return to DLMO levels. In the $4000 \mathrm{~K}$ condition, four participants 
failed to suppress plasma melatonin to their $\mathrm{DLMO}_{25} \%$ level at all and in four other participants, melatonin levels recovered to their $\mathrm{DLMO}_{25} \%$ after $\sim 1-3$ hours within the light exposure. (1.35 h, 1.67 h, 2.50 h, 3.00 h) (Figure 4)

\subsection{Phase shifting}

Both light exposure conditions caused a phase delay of the onset of the melatonin rhythm in all but of the one of the participants. Exposure to $6.5 \mathrm{~h}$ of $17000 \mathrm{~K}$ light caused a phase delay shift with amean \pm SDof $2.1 \pm 0.6 \mathrm{~h}$; $\mathrm{n}=10$ whileexposure to $4000 \mathrm{~K}$ light caused a phase delay shift of $1.7 \pm 1.3 \mathrm{~h} ; \mathrm{n}=10$. The mean differencedid not reach significance $(p=0.22)$ (Figure 3). Representative $24 \mathrm{~h}$ melatonin profiles from an individual in each of the light conditions are shown in Figure 5.

\subsection{Sleepiness assessment}

As shown in Figure 6, self-rated sleepiness was lower during the $17000 \mathrm{~K}$ light exposure as compared to the $4000 \mathrm{~K}$ group $(\mathrm{p}<0.05)$. Pre light exposure differences in KSS were not significant $(\mathrm{p}=0.20)$. Participants in the $4000 \mathrm{~K}$ light group consistently reporting being sleepier at all time points $(\mathrm{p}<0.05)$ during LE compared to the $17000 \mathrm{~K}$ light group and remained so for 3 hours post light exposure $(\mathrm{p}<0.05)$.

\subsection{Performance assessment}

With the visual PVT testing, there was no significant difference between the two light groups in the mean visual reaction time (RT) or lapses of attention during, or for the three hours after, the light exposure ended. 
Three participants were eliminated from the auditory PVT analysis for the $4000 \mathrm{~K}$ light group as their data files were corrupted due to equipment malfunction. For auditory RT, there were no significant differences in any parameter during the light exposure but there were significant differences between light conditions for RT and lapses $>400 \mathrm{msec}$ for the 3 hours post LE ( $\mathrm{p}<0.05)$, with the $17000 \mathrm{~K}$ light group having a quicker reaction time and fewer lapses than the $4000 \mathrm{~K}$ light group. This can be seen in Figure 6.

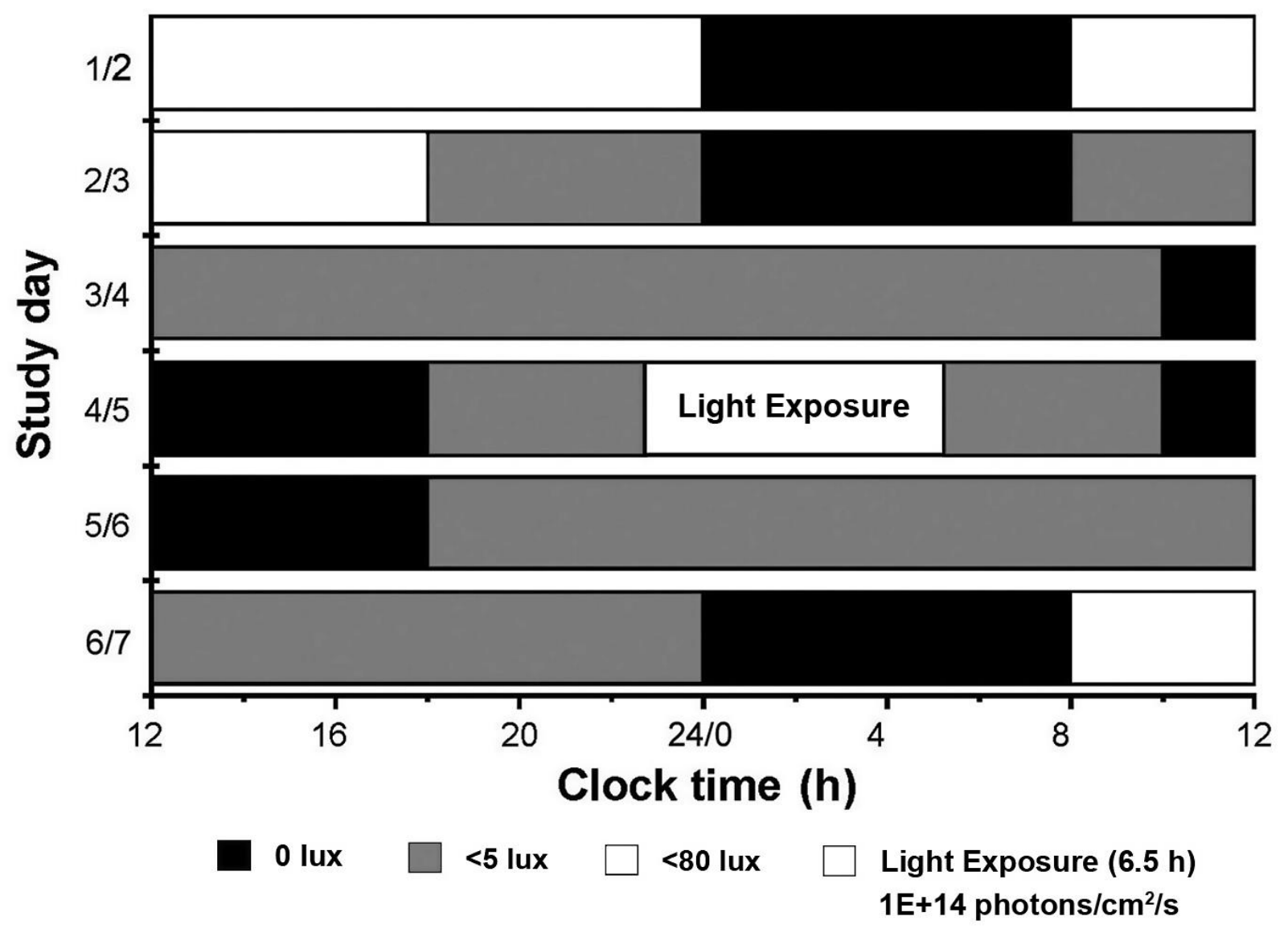


Fig. 1. Overview of 7-day phase shifting protocol for a subject with a midnight to eight AM sleep:wake schedule. The schedule consisted of a 2-day baseline (8-hour:16-hour sleep-wake cycle based on each subject's self-selected sleep-wake times), an initial 26 hour constant routine, a 16 hour dim light-exposure day with a 6.5 hour experimental light exposure, and a second 30 hour constant routine, each preceded and followed by an 8-hour sleep opportunity. [16,19].
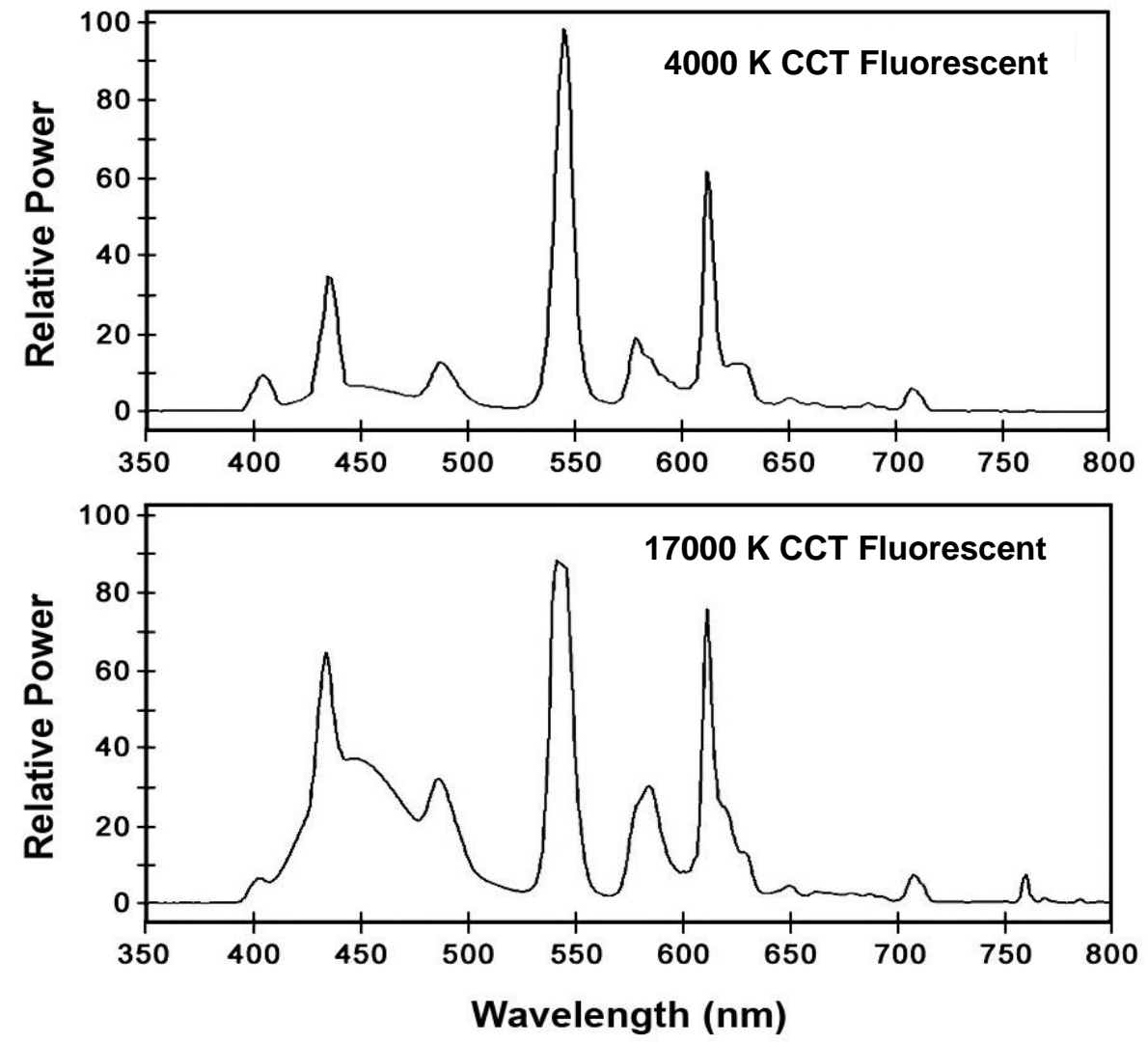
Fig. 2. Spectral power distribution for $4000 \mathrm{~K}$ (upper panel) and $17000 \mathrm{~K}$ (middle panel) light sources. Profiles are relatively similar, with the primary difference between 400 and $500 \mathrm{~nm}$. Compared to the $4000 \mathrm{~K}$ light source, the $17000 \mathrm{~K}$ light source emitted substantially more power in the blue light part of the spectrum. The lower panel shows calculated irradiances, photopic illuminances $\mathrm{v}(\lambda)$, and human photopigment illuminances relative to the two polychromatic light sources used [75].

A. Melatonin suppression

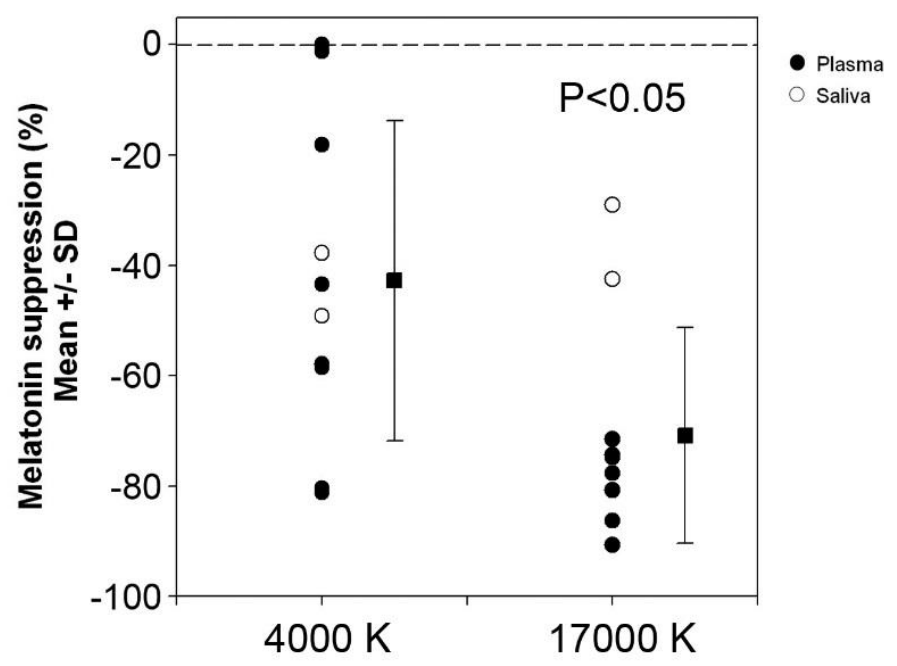

B.

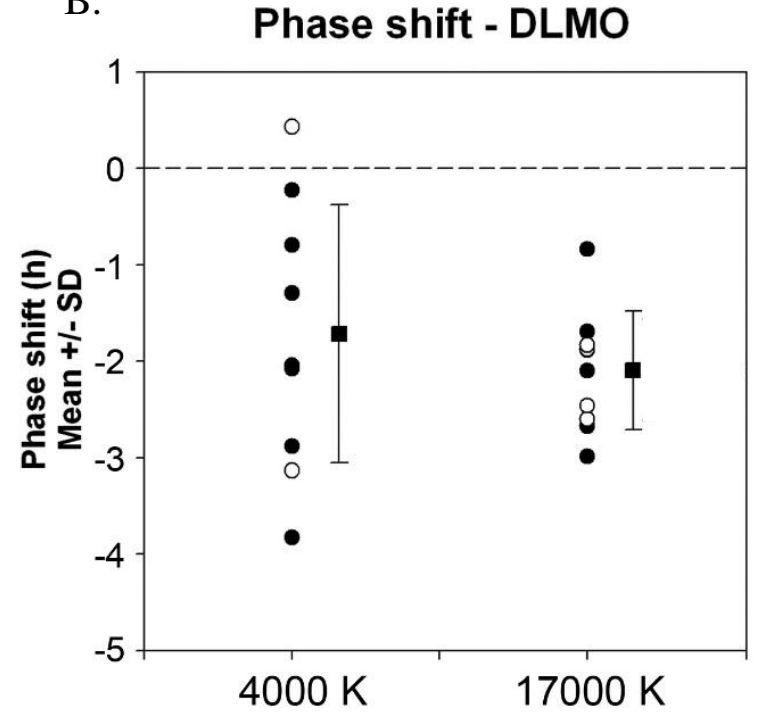


Fig. 3. Melatonin suppression $( \pm \mathrm{SD})$ as calculated by AUC with plasma (filled circles) or salivary (empty circles) levels following exposure to $6.5 \mathrm{~h}$ of white $4000 \mathrm{~K}$ fluorescent light or blue-enriched $17000 \mathrm{~K}$ fluorescent light (A). A greater suppression of plasma melatonin occurred under $17000 \mathrm{~K}$ fluorescent light compared to $4000 \mathrm{~K}$ fluorescent light $(\mathrm{p}<0.05)$. Phase delay shift $( \pm \mathrm{SD})$ of the plasma (filled circles) or salivary (empty circles) melatonin rhythm as assessed by DLMO following exposure to $6.5 \mathrm{~h}$ of white $4000 \mathrm{~K}$ fluorescent light and blue-enriched $17000 \mathrm{~K}$ fluorescent light (B). The phase delay shift, was not statistically significant $(\mathrm{p}=0.22)$.

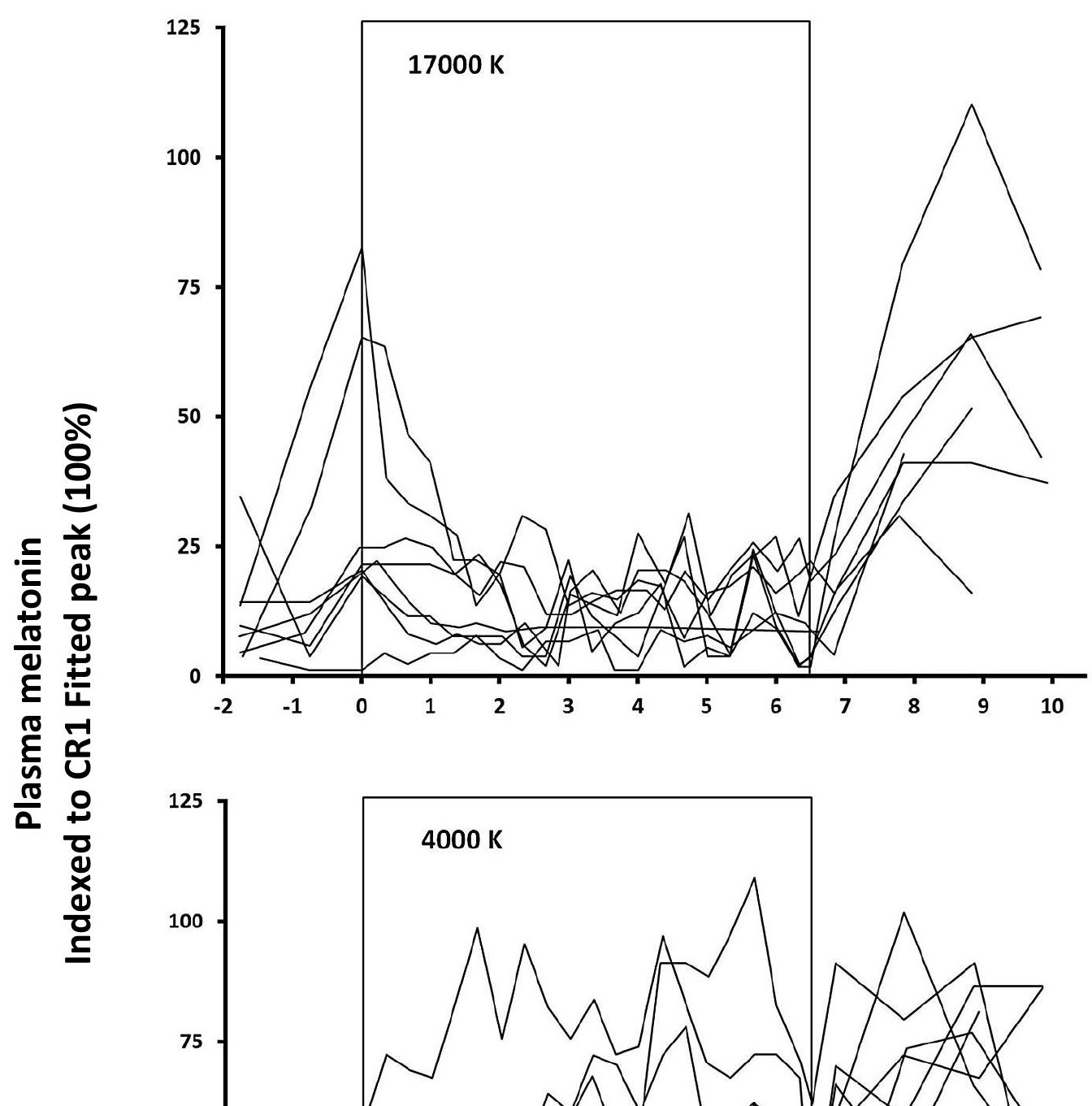




\section{Time since lights on $(\mathrm{h})$}

Fig. 4. Individual melatonin profiles $2 \mathrm{~h}$ prior to, during (boxed area) and $4 \mathrm{~h}$ after $6.5 \mathrm{~h}$ exposure to $17000 \mathrm{~K}$ (top panel) and $4000 \mathrm{~K}$ (bottom panels) light, normalized to each individuals' fitted peak value during the first melatonin cycle on CR1.
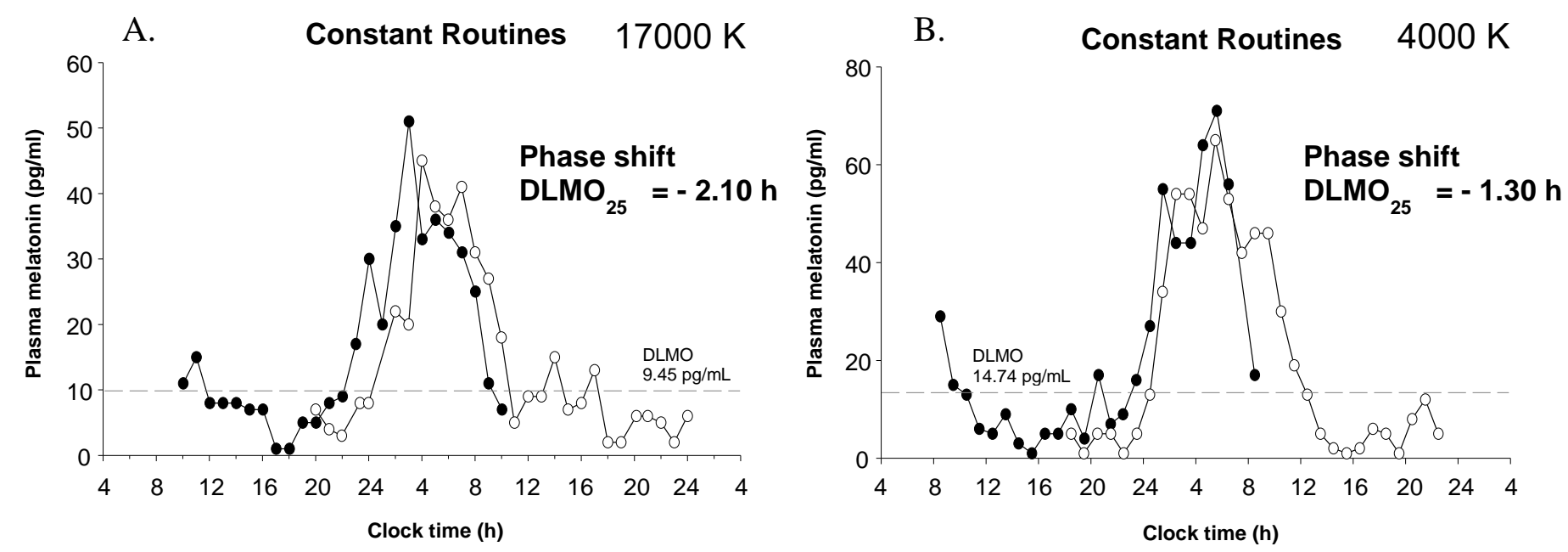

Light exposure day and

C. corresponding clock time for CR1
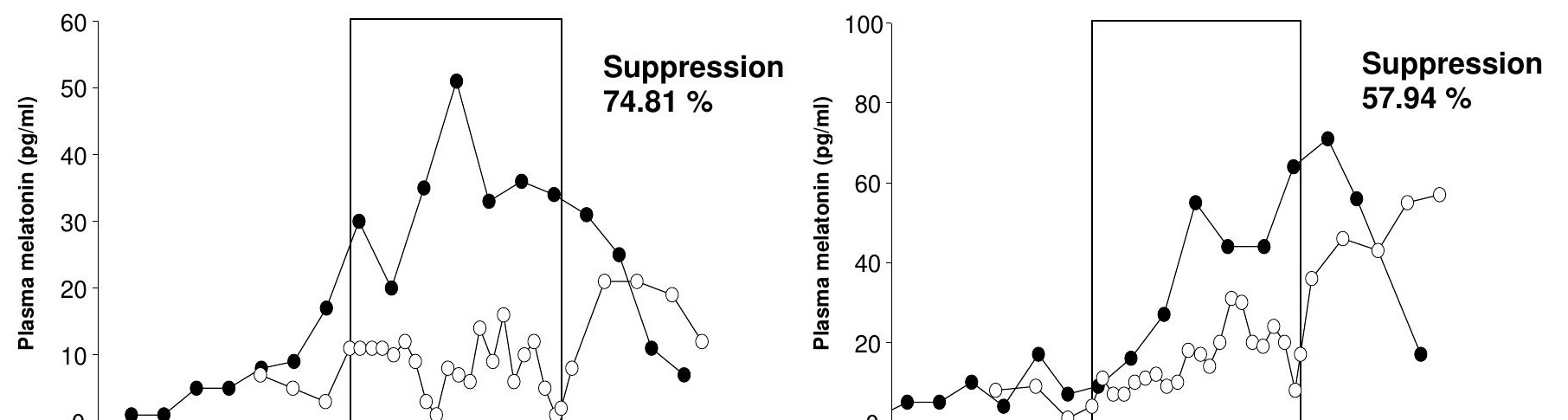
Fig. 5. The $24 \mathrm{~h}$ melatonin profiles on CR1 (filled circles) and CR2 (open circles) from one representative individual in each of the LE groups (A \& B). Below each $(C \& D)$ are the calculated melatonin suppression (AUC) during LE (open circles) and the corresponding time from CR1 (filled circles) for each of the same individuals.
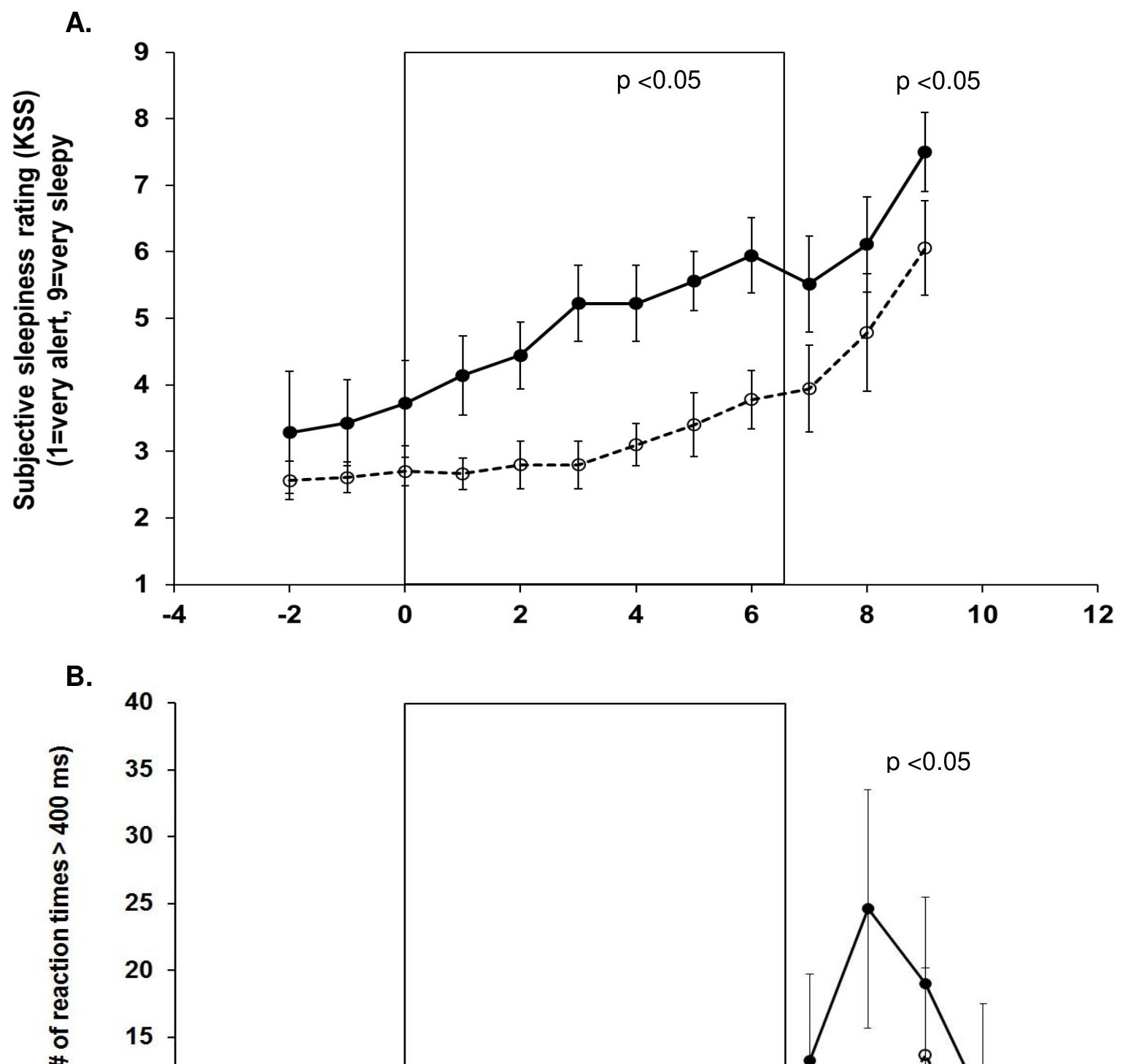
Fig. 6. KSS scores before, during and after LE (filled circles $4000 \mathrm{~K}$; open circles $17000 \mathrm{~K}$, top panel). KSS scores were lower, indicating higher alertness, during LE for the $17000 \mathrm{~K}$ group versus the $4000 \mathrm{~K}$ group $(\mathrm{p}<0.05)$. Average auditory PVT lapses per hour before, during, and after LE. The period of LE is indicated by box (bottom panel)

\section{Discussion}

Our results demonstrate that both standard $(4000 \mathrm{~K})$ and blue-enriched $(17000 \mathrm{~K})$ fluorescent light at equal photon densities of $1 \times 10^{14}$ photons $/ \mathrm{cm}^{2} / \mathrm{s}$ suppress plasma melatonin in healthy young participants with blue-enriched light eliciting a stronger hormonal suppression. In contrast, phase shifting was not significantly different at this intensity between the two light conditions. Subjective measures of alertness using KSS support the hypothesis that blue-enriched light exposure significantly improves alertness. Objective measures of alertness using PVT, however, did not show any significant differences in alertness during the light exposures. In the three hours post-light exposure 
the blue-enriched light group had quicker reaction times and fewer lapses compared to the standard light group.

This study was based on two dose-response curves for melatonin suppression which predicted the photon density at which standard and blue-enriched light would differ the most. The $\mathrm{ED}_{90}$ for the $17000 \mathrm{~K}$ dose-response curve with its matching $4000 \mathrm{~K}$ dose (approximately $\mathrm{ED}_{50}$ ) was used [28]. Use of these two dose-response curves successfully predicted the resultant melatonin suppression observed here.. The blue-enriched fluorescent light provided a significantly more consistent phase-delay than standard fluorescent light when comparing variances, however, indicating a greater effect on the circadian system. Our pre-study power calculations based on monochromatic exposure data showed sufficient power to detect an effect on phase shifting but our post-hoc power calculation revealed that these data yield a $\beta$ value of 0.797 , at $\alpha$ value of 0.05 . This is a statistical power level $(1-\beta)$ of $20.3 \%$. In order to obtain a statistical power of $50 \%$, i.e. $\beta=0.5$, each group would need to have 41 subjects, for a total of 82 subjects in the study, based upon the mean difference found between the $17000 \mathrm{~K}$ and $4000 \mathrm{~K}$ groups. The costs of running such a study would be prohibitive and is an obvious limitation to this study.

Similarly, the blue-enriched condition also had a more sustained response on melatonin suppression. When examining the time course of melatonin suppression over the 6.5 hour light exposure, the blue-enriched light was effective for the entire 6.5 hours whereas the standard lighting either failed to cause suppression or showed a loss of sensitivity over time, with melatonin returning to its DLMO level after an average of 2.15 hours. This is consistent with our previous finding that longer-wavelength monochromatic light cannot 
sustain melatonin suppression responses for more than a few hours [16,19], presumably through the inability of cone photoreceptors to maintain a maximal response [19,37]. When attempting to differentiate the relative contribution of photoreceptor systems it is useful to assess the light response over long durations in order to detect time course differences.

How classic photoreceptors participate in this phototransduction process remains an area of intensive investigation. Different types of ipRGCs with distinct retinal connections [38] further complicate the picture as perhaps these differing classes combine rod and cone inputs differentially leading to changing spectral sensitivities for the different evoked light responses. One should never assume that a light response in one area of physiology such as a neuroendocrine response like acute melatonin suppression will be predictive of another studied response such as phase shifting the circadian pacemaker. The data presented here illustrate that point.

Objective and subjective measures of alertness yielded inconsistent results. While blueenriched light exposure improved subjective alertness both during and after the light exposure compared to standard lighting, performance improvements were only seen in the three hours after the light exposure, and only for auditory reaction time and lapses. While it is not unusual for subjective and objective measures of alertness to show inconsistent changes with sleep deprivation $[39,40]$ or light exposure $[41,42]$, further work is required to understand the source of these differences, including the role of visual perception in mediating subjective responses.

A number of other comparative polychromatic light studies have also failed to find differences in phase shifting responses $[43,44,45]$. Smith and colleagues did not find 
differences in phase delay or phase advance shifts but used very high, potentially saturating light levels (4000-6000 lux, $\sim 4.2 \times 10^{15}$ photons $/ \mathrm{cm}^{2} / \mathrm{s}$ ). Munch and colleagues used a lower intensity $\left(1 \times 10^{15}\right.$ photons $\left./ \mathrm{cm}^{2} / \mathrm{s}\right)$ closer to, but still an order of magnitude higher than that used in the current study $\left(1 \times 10^{14}\right.$ photons $\left./ \mathrm{cm}^{2} / \mathrm{s}\right)$, and studied older adults who were likely to have reduced sensitivity to blue-light given pigmentation of the lens that would have blocked some of the short-wavelength light [46]. While we used a quantitative approach in selecting our light intensity, basing it on short-duration fluence response curves for melatonin suppression using the same light sources, it is possible that i) short duration exposures (1.5 h) do not always predict the effects of longer duration light (6.5 h) [19]; ii) the magnitude of melatonin suppression does not predict the magnitude of circadian phase shifting or vice versa $[47,48]$. Our pre-study power calculations based on monochromatic exposure data showed sufficient power to detect an effect on phase shifting but our posthoc power calculation for phase shifting, based on the actual variances measured, suggested that a greater number of participants was required.

The blue enriched light source used appears to be more efficient for photic phase shifting than the standard light source. Results were compared with a prior white light PRC [8] and indicated that the blue enriched light stimulus achieved approximately $80 \%$ of the phase shifting response of the much brighter $\left(3,000 \mu \mathrm{W} / \mathrm{cm}^{2}\right)$ white light stimulus with the maximum phase-delay of $-2.6 \mathrm{~h}$ while the standard light stimulus achieved $25 \%$ less. In our study, we used less than $2 \%\left(50 \mu \mathrm{W} / \mathrm{cm}^{2}\right)$ of the energy of the white light stimulus reported in the PRC study.

The melatonin suppression data presented here are similar to the melatonin suppression results of other studies comparing $4000 \mathrm{~K}$ and $17000 \mathrm{~K}$ fluorescent lights. Specifically, 
compared to the $4000 \mathrm{~K}$ light, $17000 \mathrm{~K}$ light was significantly stronger in suppressing melatonin in healthy subjects $[28,49]$. Melatonin suppression has been a widely used marker to discern physiology of melatonin and circadian regulation [50]. Importantly, melatonin suppression by light is suspected to be oncogenic [51] as well as possibly contributing to a range of other disorders [52]. Strict numerical comparison of melatonin suppression values across these studies, however, is not warranted due to major protocol differences such as circadian time of light exposure, prior photic history, light exposure duration and light source geometry $[8,53,54,55,56]$.

Many studies, but not all [57,58], have shown that polychromatic light increases alertness and improves performance in neurobehavioral tests compared to dim light or darkness. The study reported here uses equal photon doses of relatively dim light. A dark control condition may have yielded significant results. Studies using polychromatic light reported alerting effects when used at night $[59,60,61,62]$. Neurobehavioral and physiological parameters affected by nocturnal bright light exposure include subjective sleepiness, EEG frequencies in the beta, theta and alpha ranges, psychomotor vigilance performance, and a variety of cognitive tests. These effects have also been shown for daytime exposure $[63,64]$ consistent with a separation of the mechanisms underpinning the alertness-enhancing and melatonin suppression responses of light, at least during the day.

When comparing the alerting effects of light with different spectra, a less consistent view emerges. In controlled laboratory studies of monochromatic, narrow-band light and polychromatic light, short-wavelength sensitivity to the alerting effects of light on subjective and objective measures have been shown in a range of models and different times of day $[65,66,67]$. Similarly, the benefits of blue-enriched daytime light exposure on 
alertness, performance, mood and cognition have been seen in real-world settings such as schools, offices and care homes $[23,24,25,26,27,68]$ and in clinical groups $[69,70]$. Other studies, however, have failed to show major differences in alertness and/or performance measures between different narrow-band or polychromatic sources during the day [39,71] or night [41].

Major differences in populations studied, parameters measured, light history experienced, timing of light exposure given and intensities employed all likely contribute to these findings. While there is likely too much variability between studies to conduct a formal review of the alerting effects of light at this time, the weight of evidence suggests that blue or blue-enriched lighting is likely to be beneficial for alertness and performance compared to spectra with less short-wavelength light, all else being equal.

Modeling these effects of light, or designing lighting to take advantage of these benefits in real world application, presents a challenge. There are multiple factors that affect these responses to light, including circadian timing, light intensity, wavelength and duration, but the field does not have a complete knowledge of all relevant factors behind such effects. While models have been proposed to try and predict the relative efficacy of a particular light stimulus in terms of its relative circadian, neuroendocrine, and neurobehavioral efficacy $[72,73,74]$ caution must be exercised as our understanding of circadian phototransduction develops.

Lack of a consistent and adequate method of quantifying light between different laboratories publishing data on photic regulation of biological and behavioral responses can make it challenging to replicate experimental conditions or to compare across studies. A number of laboratories have collaborated on developing a consensus publication about 
measuring light for circadian, neuroendocrine and neurobehavioral regulation based on current and accepted sensitivity functions for rods, cones and melanopsin integrating the spectral power distribution of the source [75] and the Commission Internationale de l'Eclairage recently adopted the consensus publication and accompanying free Toolbox as an international standard [76]. Light source data are reported in the Figure 2 using the Toolbox described by Lucas and colleagues [75]. While quantification of the biological potency of light for non-visual photoreception is developing, collecting source descriptions on one platform will help for comparing results and developing testable hypotheses that predict spectral characteristics for targeted physiological responses to polychromatic light. Care must be taken to appropriately describe and measure the lighting conditions so as to inform the lighting community and foster intelligent design. Careful measurement of the incident light spectrum being studied is crucial and must be reported in a systematic way. To this end, the consensus methodology described by Lucas and colleagues [75] with use of a common nomenclature based on current and accepted sensitivity functions will open the door for researchers to continue to unravel this complex photosensory system. Meanwhile, empirical verification of specific light stimuli will remain the most accurate way to determine the biological potency of light sources.

\section{Funding}

Primary research support was provided by the National Space Biomedical Research Institute through NASA NCC 9-58. Additional support was provided by the Philadelphia Section of the Illuminating Engineering Society.

\section{Acknowledgments}

We are grateful for the support of Gerrit van den Beld, Luc Schlangen, Ph.D., and George 
Kok of Philips Lighting in providing the study lamps and ballasts as well as Jim Yorgey of Lutron Electronics for their generous donation of the test facility light dimming system. We appreciate the assistance of David H. Sliney, Ph.D., who performed the light source hazard analyses as a consultant. A sincere thanks is given to our colleagues from Brigham and Women's Hospital for training the Thomas Jefferson University Light Research Program staff on the proper execution of the multiple day studies. We are grateful to Rob Lucas, Ph.D., Stuart Peirson, Ph.D., Luke Price, Ignacio Provencio, Ph.D., and Jamie Zeitzer, Ph.D., for discussions and insights related to these studies. The study reported here was a chapter in the first authors' Ph.D. thesis. We are thankful to Debra Skene, Ph.D., Simon Archer, Ph.D. and Kenneth Wright, Jr., Ph.D. for their extensive editorial assistance with thesis preparation. We thank Bill Coyle, Kymberlee Milligan, Nick Kurczewski, Jessica Treadway, Tyisha Vincent, Trisha Juliano, Rich Kiok, Chris Stange, Benjamin Chung, Nathan Avery, Shalini Vadalia, Talia Glodjo and Veronica Salber for their invaluable assistance in completing this research.

\section{References}

[1] Zeitzer JM, Dijk D-J, Kronauer RE, Brown EN and Czeisler CA (2000) Sensitivity of the human circadian pacemaker to nocturnal light: melatonin phase resetting and suppression. J Physiol 526:695-702.

[2] Moore RY (1983) Organization and function of a central nervous system circadian oscillator: the suprachiasmatic hypothalamic nucleus. Federation Proceedings 42:27832789. 
[3] Czeisler CA, Shanahan TL, Klerman EB, Martens H, Brotman DJ, Emens JS, Klein T and Rizzo JF, III (1995) Suppression of melatonin secretion in some blind patients by exposure to bright light. $N$ Engl J Med 332:6-11.

[4] Lockley SW, Skene DJ, Arendt J, Tabandeh H, Bird AC and Defrace R (1997) Relationship between melatonin rhythms and visual loss in the blind. J Clin Endocrinol Metab 82:3763-3770.

[5] Czeisler CA and Gooley JJ (2007) Sleep and circadian rhythms in humans. Cold Spring Harb Symp Quant Biol 72:579-597.

[6] Arendt J (1995) Melatonin and the Mammalian Pineal Gland, Chapman and Hill, London.

[7] Lewy AJ, Wehr TA, Goodwin FK, Newsome DA, and Markey SP (1980) Light suppresses melatonin secretion in humans. Science 210:1267-1269.

[8] Khalsa SB, Jewett ME, Cajochen C and Czeisler CA (2003) A phase response curve to single bright light pulses in human subjects. J Physiol 549:945-952.

[9] Lewy AJ and Sack RL (1989) The dim light melatonin onset as a marker for circadian phase position. Chronobiol Int 6:93-102.

[10] Provencio I, Rodriguez IR, Jiang G, Hayes WP, Moreira EF and Rollag MD (2000) A novel human opsin in the inner retina. $J$ Neurosci 20:600-605.

[11] Gooley JJ, Lu J, Chou TC, Scammell TE and Saper CB (2001) Melanopsin in cell of origin of the retinohypothalamic tract. Nature Neurosci 4:1165.

[12] Berson DM, Dunn FA and Takao M (2002) Phototransduction by retinal ganglion cells that set the circadian clock. Science 295:1070-1073. 
[13] Hattar S, Liao H-W, Takao M, Berson DM and Yau K-W (2002) Melanopsincontaining retinal ganglion cells: architecture, projections, and intrinsic photosensitivity. Science 295:1065-1070.

[14] Brainard GC, Hanifin JP, Greeson JM, Byrne B, Glickman G, Gerner E, and Rollag MD (2001) Action spectrum for melatonin regulation in humans: evidence for a novel circadian photoreceptor. J Neurosci 21:6405-6412.

[15] Thapan K, Arendt J and Skene DJ (2001) An action spectrum for melatonin suppression: evidence for a novel non-rod, non-cone photoreceptor system in humans. $J$ Physiol 535:261-267.

[16] Lockley SW, Brainard GC and Czeisler CA (2003) High sensitivity of the human circadian melatonin rhythm to resetting by short wavelength light. J Clin Endocrinol Metab $88: 4502-4505$.

[17] Warman VL, Dijk D-J, Warman GR, Arendt J and Skene DJ (2003) Phase advancing human circadian rhythms with short wavelength light. Neurosci Lett 342:37-40.

[18] Cajochen C, Munch M, Kobialka S, Krauchi K, Steiner R, Oelhafen P, Orgul S and Wirz-Justice A (2005) High sensitivity of human melatonin, alertness, thermoregulation, and heart rate to short wavelength light. J Clin Endocrinol Metab 90:1311-1316.

[19] Gooley JJ, Rajaratnam SM, Brainard GC, Kronauer RE, Czeisler CA and Lockley SW (2010) Spectral responses of the human circadian system depend on the irradiance and duration of exposure to light. Sci Transl Med 2:31ra33.

[20] Rahman SA, Flynn-Evans EE, Aeschbach D, Brainard GC, Czeisler CA and Lockley SW (2014) Diurnal spectral sensitivity of the acute alerting effects of light. Sleep 37:271281. 
[21] Morita T and Tokura H (1996) Effects of lights of different color temperature on the nocturnal changes in core temperature and melatonin in humans. Appl Human Sci 15:243246.

[22] Sato M, Sakaguchi T and Morita T (2005) The effects of exposure in the morning to light of different color temperatures on the behavior of core temperature and melatonin secretion in humans. Biol Rhythm Res 36:278-292.

[23] Viola AU, L.M. J, Schlangen LJM and Dijk DJ (2008) Blue-enriched white light in the workplace improves self-reported alertness, performance and sleep quality. Scand $J$ Work Environ Health 34:297-306.

[24] Barkmann C, Wessolowski N and Schulte-Markwort M (2012) Appicability and efficacy of variable light in schools. Physiol Behav 105:621-627.

[25] Mott MS, Robinson DH, Walden A, Burnette J and Rutherford AS (2012) Illuminating the effects of dynamic lighting on student learning. Sage Open 2:doi: $10.1177 / 2158244012445585$.

[26] Sleegers PJC, Moolenaar NM, Galetzka M, Pruyn A, Sarroukh BE and van der Zande B (2013) Lighting affect students' concentration positively: findings from three Dutch studies. Lighting Res and Technol 45:159-175.

[27] Keis O, Helbig H, Streb J and Hille K (2014) Influence of blue-enriched classroom lighting on students' cognitive performance. Trends Neurosci Educ 3:86-92.

[28] Brainard GC, Hanifin JP, Warfield B, Stone MK, James ME, Ayers M, Kubey A, Byrne B and Rollag M (2015) Short wavelength enrichment of polychromatic light enhances human melatonin suppression potency. J Pineal Res 58:352-361. 
[29] Akerstedt T and Gillberg M (1990) Subjective and objective sleepiness in the active individual. Int J Neurosci 52:29-37.

[30] Dinges DF and Powell JW (1985) Microcomputer analyses of performance on a portable, simple visual RT task during sustained operations. Behav Res Methods Instrum Comput 17:652-655.

[31] Dinges DF and Kribbs NB (1991) Performing while sleepy: effects of experimentally-induced sleepiness. In Sleep, Sleepiness and Performance, TH Monk, ed, pp 97-128, John Wiley and Sons, Chichester, England.

[32] Lim J and Dinges DF (2008) Sleep deprivation and vigilant attention. Ann N Y Acad Sci 1129:305-322.

[33] Lamond N, Jay SM, Dorrian J, Ferguson SA, Roach GD and Dawson D (2008) The sensitivity of a palm-based psychomotor vigilance task to severe sleep loss. Behav Res Meth 40:347-352.

[34] Rollag, M.D. and G.D. Niswender (1976). Radioimmunoassay of serum concentrations of melatonin in sheep exposed to different lighting regimens. Endocrinology 98:482-489.

[35] Vaughan GM (1993) New sensitive serum melatonin radioimmunoassay employing the Kennaway G280 antibody: Syrian hamster morning adrenergic response. J Pineal Res 15:88-103.

[36] Cohen J (1988) Statistical Power Analysis for the Behavioral Sciences. 2nd ed., Erlbaum, Hillsdale, New Jersey.

[37] Zaidi FH, Hull JT, Peirson SN, Wulff K, Aeschbach D, Gooley JJ, Brainard GC, Gregory-Evans K, Rizzo JF, Czeisler CA, Foster RG, Moseley MJ and Lockley SW (2007) 
Short-wavelength light sensitivity of circadian, pupillary, and visual awareness in humans lacking an outer retina. Curr Biol 17:2122-2128.

[38] Schmidt TM and Kofuji P (2011) Structure and function of bistratified intrinsically photosensitive retinal ganglion cells in the mouse. J Comp Neurol 519:1492-1504.

[39] Van Dongen HP, Maislin G, Mullington JM and Dinges DF (2003) The cumulative cost of additional wakefulness: dose-response effects on neurobehavioral functions and sleep physiology from chronic sleep restriction and total sleep deprivation. Sleep 26:117126.

[40] St. Hilaire MA, Ruger M, Fratelli F, Hull JT, Phillips AJ and Lockley SW (2017) Modeling neurocognitive decline and recovery during repeated cycles of extended sleep and chronic sleep deficiency. Sleep 40:doi: 10.1093/sleep/zsw1009.

[41] Revell VL, Arendt J, Fogg LF and Skene DJ (2006) Alerting effects of light are sensitive to very short wavelengths. Neurosci Lett 399:96-100.

[42] Sletten TL, Ftouni S, Nicholas CL, Magee M, Grunstein RR, Ferguson S, Kennaway DJ, O'Brien D, Lockley SW and Rajaratnam SMW (2017) Randomised controlled trial of the efficacy of a blue-enriched light intervention to improve alertness and performance in night shift workers. Occup Environ Med:Jun 19. doi: 10.1136/oemed-2016-103818.

[43] Smith MR and Eastman CI (2009) Phase delaying the human circadian clock with blue-enriched polychromatic light. Chronobiol Int 26:709-725.

[44] Smith MR, Revell VL and Eastman CI (2009) Phase advancing the human circadian clock with blue-enriched polychromatic light. Sleep Med 10:287-294. 
[45] Munch M, Scheuermaier KD, Zhang R, Dunne SP, Guzik AM, Silva EJ, Rhonda JM and Duffy JF (2011) Effects on subjective and objective alertness and sleep in response to evening light exposure in older subjects. Behav Brain Res 224:272-278.

[46] Barker FM, Brainard GC and Dayhaw-Barker P (1991) Transmittance of the human lens as a function of age. Invest Ophthalmol Vis Sci 32:1083.

[47] Rahman S, St. Hilaire M, Gronfier C, Chang A-M, Santhi N, Czeisler C, Klerman E and Lockley S (2018) Functional decoupling of melatonin suppression and circadian phase resetting in humans. J Physiol (Lond), 596:214-2157.

[48] Najjar RP and Zeitzer JM (2016) Temporal integration of light flashes by the human circadian system. J Clin Invest 126:938-947.

[49] Santhi N, Thorne HC, van der Veen DR, Johnsen S, Mills SL, Hommes V, Schlangen LJM, Archer SN and Dijk DJ (2012) The spectral composition of evening light and individual differences in the suppression of melatonin and delay of sleep in humans. $J$ Pineal Res 53:47-59.

[50] Brainard GC, Rollag MD and Hanifin JP (1997) Photic regulation of melatonin in humans: ocular and neural signal transduction. J Biol Rhythms 12:537-546.

[51] Blask DE, Brainard GC, Dauchy RT, Hanifin JP, Davidson LK, Krause JA, Sauer LA, Rivera-Bermudez MA, Dubocovich ML, Jasser SA, Lynch DT, Rollag MD and Zalatan F (2005) Melatonin-depleted blood from premenopausal women exposed to light at night stimulates growth of human breast cancer xenografts in nude rats. Cancer Res 65:1117411184. 
[52] Stevens RG, Brainard GC, Blask DE, Lockley SW and Motta ME (2013) Adverse health effects of nighttime lighting: comments on american medical association policy statement. Am J Prev Med 45:343-346.

[53] Hebert M, Martin SK, Lee C and Eastman CI (2002) The effects of prior light history on the suppression of melatonin by light in humans. J Pineal Res 33:198-203.

[54] Smith KA, Schoen MW and Czeisler CA (2004) Adaptation of human pineal melatonin suppression by recent photic history. J Clin Endocrinol Metab 89:3610-3614.

[55] Jasser SA, Hanifin JP, Rollag MD and Brainard GC (2006) Dim light adaptation attenuates acute melatonin suppression in humans. J Biol Rhythms 21:394-404.

[56] French J, Hannon P and Brainard GC (1990) Effects of bright illuminance on body temperature and human performance. Annu Rev Chronopharmacol 7:37-40.

[57] Dollins AB, Lynch HJ, Wurtman RJ, Deng MH and Lieberman HR (1993) Effects of illumination on human nocturnal serum melatonin levels and performance. Physiol Behav 53:153-160.

[58] Badia P, Myers B, Boecker M and Culpepper J (1991) Bright light effects on body temperature, alertness, EEG, and behavior. Physiol Behav 50:583-588.

[59] Myers B and Badia P (1993) Immediate effects of different light intensities on body temperature and alertness. Physiol Behav 54:199-202.

[60] Wright KP, Badia P, Myers BL and Plenzler SC (1997) Combination of bright light and caffeine as a countermeasure for impaired alertness and performance during extended sleep deprivation. J Sleep Res 6:26-35. 
[61] Cajochen C, Zeitzer JM, Czeisler CA and Dijk D-J (2000) Dose-response relationship for light intensity and ocular and electroencephalographic correlates of human alertness. Behav Brain Res 115:75-83.

[62] Phipps-Nelson J, Redman JR, Dijk DJ and Rajaratnam SM (2003) Daytime exposure to bright light, as compared to dim light, decreases sleepiness and improves psychomotor vigilance performance. Sleep 26:695-700.

[63] Ruger M, Gordijn MC, Beersma DG, De Vries B and Daan S (2006) Time-of-daydependent effects of bright light exposure on human psychophysiology: comparison of daytime and nighttime exposure. Am J Physiol Regul Integr Comp Physiol 290:R1413R1420.

[64] Cajochen C (2007) Alerting effects of light. Sleep Med Rev 11:453-464.

[65] Phipps-Nelson J, Redman JR, Schlangen LM and Rajaratnam SM (2009) Blue light exposure reduces objective measures of sleepiness during prolonged nighttime performance testing. Chronobiol Int 26:891-912.

[66] Chellappa SL, Steiner R, Blattner P, Oelhafen P, Gotz T and Cajochen C (2011) Nonvisual effects of light on melatonin, alertness and cognitive performance: can blueenriched light keep us alert? PLOS ONE 6:e16429.

[67] Chellappa SL, Steiner R, Oelhafen P, Lang D, Gotz T, Krebs J and Cajochen C (2013) Acute exposure to evening blue-enriched light impacts on human sleep. J Sleep Res 22:573-580.

[68] Figueiro MG, Plitnick BA, Lok A, Jones GE, Higgins P, Hornick TR and Rea MS (2014) Tailored lighting intervention improves measures of sleep, depression, and agitation 
in persons with Alzheimer's disease and related dementia living in long-term care facilities. Clin Interv Aging 9:1527-1537.

[69] Sinclair KL, Ponsford JL, Taffe J, Lockley SW and Rajaratnam SMW (2014) Randomized controlled trial of light therapy for fatigue following traumatic brain injury. Neurorehabil Neural Repair 28:303-313.

[70] Redd WH, Valdimarsdottir H, Wu L, Winkel G, Byrne EE, Beltre MA, Liebman ES, Erazo T, Hayes JA, Isola L, Scigliano E, Meschian Y, Lutgendorf S and Ancoli-Israel S (2014) Systematic light exposure in the treatment of cancer-related fatigue: a preliminary study. Psychooncology 23:1431-1434.

[71] Segal AY, Sletten TL, Flynn-Evans EE, Lockley SW and Rajaratnam SMW (2016) Daytime exposure to short- and medium-wavelength light did not improve alertness and neurobehavioral performance. J Biol Rhythms 31:470-482.

[72] Gall D and Bieske K (2004) Definition and measurement of circadian radiometric quantities. In Symposium '04 'Light and Health: non-visual effects, x027:2004, pp 129136, Commission Internationale de l'Eclairage, Vienna.

[73] Rea MS, Figueiro MG, Bullough JD and Bierman A (2005) A model of phototransduction by the human circadian system. Brain Res Brain Res Rev 50:213-228.

[74] Deutsches Institut Fur Normung (2009) Optical radiation physics and illuminating engineering - Part 100: Non-visual effects of ocular light on human beings - Quantities, symbols and action spectra. Berlin: Deutsches Institut Fur Normung, DIN V 5031-100, pp $1-16$.

[75] Lucas RJ, Peirson SN, Berson DM, Brown TM, Cooper HM, Czeisler CA, Figueiro MG, Gamlin PD, Lockley SW, O'Hagan JB, Price LLA, Provencio I, Skene DJ and 
Brainard GC (2014) Measuring and using light in the melanopsin age. Trends Neurosci $37: 1-9$.

[76] Commission Internationale de l'Eclairage (2015) Technical Note, Report on the First International Workshop on Circadian and Neurophysiological Photometry, 2013, Commission Internationale de l'Eclairage, Vienna.

\section{Competing Interest}

JPH has no conflicts of interests related to the research or results reported in this paper. In the interests of full disclosure, however, he reports that through Thomas Jefferson University, his laboratory has received equipment, advice, or financial support from the IESNA Philadelphia Chapter; PhotoPharmics; and BIOS. In the past year, he has receive travel support from the Department of Energy and The National Science Foundation.

SWL has no conflicts of interests related to the research or results reported in this paper. In the interests of full disclosure, commercial interests from the last 3 years (2015-2018) are listed below. SWL has received consulting fees from the Atlanta Falcons, Atlanta Hawks, Pegasus Capital Advisors LP, Serrado Capital, Slingshot Insights; and has current consulting contracts with Akili Interactive, Consumer Sleep Solutions, Delos Living LLC, Headwaters Inc., Hintsa Performance AG, Light Cognitive, Lighting Science Group Corporation, Mental Workout, PlanLED, OpTerra Energy Services Inc., Six Senses, Wyle Integrated Science and Engineering. SWL has received unrestricted equipment gifts from Biological Illuminations LLC, Bionetics Corporation and F.Lux Software LLC; has equity 
in iSLEEP, Pty; advance author payment and/or royalties from Oxford University Press; honoraria plus travel, accommodation and/or meals for invited seminars, conference presentations or teaching from BHP Billiton, Lightfair, Informa Exhibitions (USGBC), Teague; travel, accommodation and/or meals only (no honoraria) for invited seminars, conference presentations or teaching from DIN, FASEB, Lightfair, SLTBR and USGBC. SWL has completed an investigator-initiated research grant from Biological Illumination LLC and has an ongoing investigator initiated grant from F. Lux Software LLC. SWL holds a process patent for 'Systems and methods for determining and/or controlling sleep quality', which is assigned to the Brigham and Women's Hospital per Hospital policy. SWL has also served as a paid expert for legal proceedings related to light, sleep and health. SWL is also a Program Leader for the CRC for Alertness, Safety and Productivity, Australia. GCB has no conflicts of interests related to the research or results reported in this paper. In the interests of full disclosure, however, he reports that through Thomas Jefferson University, his laboratory has received equipment, advice, or financial support from the IESNA Philadelphia Chapter; Panasonic, OSRAM-Sylvania, Philips Lighting; Lutron, Lighting Sciences Group, Apollo Lighting; PhotoPharmics; BioBrite Inc., BIOS and Litebook. In the past year, he has receive travel support from the Department of Energy, The National Science Foundation, The University of California San Diego, DIN (Germany), The Society for Light Treatment and Biological Rhythms, The Rowe Lectureship, and The Institute for Integrative Health. He holds two currently issued patents (USPTO \#09/853,428 and \#8,366,755) and two continuing patent applications (USPTO \#09/853,428 and World PCT 2005/004948AZ). 